\title{
LYOTARD AND THE OIKOS
}

\section{By Gregory Kalyniuk (Trent University)}

In The Postmodern Condition, Jean-François Lyotard criticises Niklas Luhmann for making performativity or context-control the goal of systems, claiming that this legitimates the exclusion of partners constituting the context of a system from the decision-making process which administrates it (Lyotard, 1984: 60 ff.). In "Oikos," Lyotard takes this criticism a step further when he relates the context or environment of the system and the partners constituting it to the etymological root of "ecology," the oikeion, which stands for the asymmetrical relation of familiarity with or knowledge of something or someone. As the entropic source of the system's performativity and "reduction of complexity," the oikeion refers to the alter of undermined humanity as well as other forms of life, whose selective attention is not sufficiently capable or developed to act as ego or be addressed as alter-ego by a receiver within the social system. Lyotard's approach is not to reaffirm the dualism of Man and Nature, but to instead detect the differend produced by its dissociation from the "inside" of system and the "outside" of environment - for the system is no more like Man than its environment is like Nature in Systemtheorie. Rather, everything is Nature, and those who are able to put its potential into action most efficiently are able to assume the secure position of "Man" in the humanistic war against those who lack this efficiency. Lyotard aims to listen to those who have lost power over their oikos, or the "inside" which has become somebody else's "outside." 
For Lyotard, the opposition between Man and Nature and the characterisation of Man as "inside" and Nature as "outside" form the basis for a Hegelian metaphysics of the subject, which posits the objectification of thought, perception, and speech as conditions for human action (Lyotard, 1993: 97). Against this conception, he identifies a metaphysics of substance originating with Aristotle, which distinguishes potential from action relative to a concept of energy, replacing the border between inside and outside with a distinction between form and matter. In The Inhuman and later in "Oikos," Lyotard identifies the thought of Leibniz as the extreme condition of this kind of philosophy, since it dissolves the border between objective matter and subjective thought (Lyotard, 1988: 5, 39 ff.; Lyotard, 1993: 98). For Leibniz, consciousness is matter with a high degree of memory, while matter is "momentary mind," or the lowest degree of memory. Monads, the spiritual substances of Leibniz's philosophy, are similar in the sense that the whole world is reflected through each of them, but different in the sense that they each form a unique perspective on the world, which is determined by their level of complexity and their capacity to make use of memory in the processing of information. If humanity could be conceived as a monad, claims Lyotard, then techno-scientific advancement has resulted in this monad acquiring an increasingly complex memory. Leibniz had envisioned that such advancement would result in the amplified reason of the characteristica universalis and calculus ratiocinator, illuminating the choices of the divine monad in selecting the best possible world with the greatest diversity of monads and the least quantity of suffering. He believed that this discovery would be the last effort of the human spirit before the emergence of a utopian world in which justice would become the object of a rigourous science (Leibniz, 1976: 76). The contemporary result of 
such advancement, however, has instead seen a splintering of so-called realities within the same world with the emergence of such ideologies as Systemtheorie, which claims to describe the selection of just such a best possible world, but according to the criteria of capitalist performativity rather than divine charity. Lyotard's oikeion would then refer to the realities which get left behind, or the unnameable of the characteristica universalis and the unquantifiable of the calculus ratiocinator - problems which the human spirit tends to forget about in its utopian, techno-scientific ascent.

The capacity to make use of the complex memory which techno-scientific advancement has made possible is characterised as the "reduction of complexity" in the Systemtheorie of Luhmann, who develops applications for the reflexive feedback loops of cybernetics in the domain of sociology. A feedback loop is a process by which a variable quantity of the output is fed back into the input of a system, modifying or amplifying the initial input signal, and a system is a set of interacting parts distinguished from their environment by a boundary which forms them into a closed, interconnected whole. Luhmann posits social and psychical systems as autopoietically closed zones of reduced complexity constituted in relation to a chaotic environment which feeds them information. Communicative actions select a limited quantity of information from the chaos and process it into meaning, which maintains the identity of the system and its boundary against the chaos. The element of feedback comes into play with the selective component of this process. A relation of structural coupling is posited to account for the reciprocal compensation of influence between psychical and social systems, or the way in which people are the environment of society no less than society is the environment of people. The consequence of this is that the communicative actions of people are 
constituted not by the people, but the society, which is in turn constituted by their communicative actions. Communication can only be apprehended self-referentially, and whatever is not apprehended as communication remains in the environment. Agency and innovation are still possible, but only when the feedback loop of the individual selects and processes meaning better than the feedback loop of society with which it is structurally coupled.

Leibniz's concept of the individual, or rather his notion of the individual concept, needs some further explication in relation to the oikeion and oikos. Reversing the order of the formula which determines the truth of analytic predication (subject-predicate) into one which asserts all truth as analytic predication, Leibniz arrives at the principle of sufficient reason. Everything which is or can be analysed to be true about a subject, meaning all of the relations which it forms and all of the events which it can undergo, are already contained within the individual concept of that subject. Sufficient reason holds that each subject has such an individual concept, which contains all of these relations and events as its predicates. Leibniz makes a distinction between necessary predicates which are genetic to the singular individual, and contingent predicates which are only incarnated through substantial relations with other monads, or appurtenances. These could range from the simple monads which belong to the parts of the individual's body to the simple monads which belong to other bodies, as well as other thinking monads. The substantial relations between singular and appurtenant monads are decomposable but renewable, and a favourite example of Leibniz's is the ship of Theseus which the Athenians were always repairing (Deleuze, 1993: 110). In this sense the theory of appurtenance explains possession and having, while the oikeion, as we shall see, stands for the inverted relation, 
or the not-having of the naked and dispossessed monads which fall at the fringes of another monad's sphere of appurtenance.

Within Systemtheorie, Lyotard identifies the realisation of Leibniz's monadology in the form of a general physics of developing systems. Conceived monadologically, larger, composite systems lose priority to the monadic "sub-systems" which constitute them, while the psychic dissolves into the social - everything becomes a society, as Gabriel Tarde would have proclaimed. Against the notion that the "reduction of complexity" could arise between humanity and nature as though it were a suppression of complexity, Lyotard instead proposes that it arises between more developed cultures and less developed cultures. The West for instance increases its capacity to make use of complex information at the expense of the Third World which it dominates (Lyotard, 1993: 99). Falling within its sphere of appurtenance, the Third World becomes the source of entropy for the autopoiesis of the great monad of the West, in the same sense that the negentropic reduction of complexity in more highly developed systems could be made possible by the entropic failure to select information and process meaning in less developed systems. The mistake of Systemtheorie lies in confusing the source of this entropy with a global nature as conceived in opposition to a global humanity, when it really inhabits that section of labouring humanity whose development is inhibited for the benefit of affluent humanity. Lyotard identifies this entropy with the oikeion, or what Aristotle describes as the familiarity which parents recognise in their children, which children do not necessarily recognise in their parents. The meaning of oikeion is extended into oikos, which denotes the household or home. While Lyotard describes the Third World as oikeion to the West in the context of his monadological interpretation of the 
"reduction of complexity", he also emphasises that oikos is not the place of safety but the place of tragedy. The structural coupling between affluent Westerners and child labourers in the Third World is like a dysfunctional family or a broken home - the parents cannot tell the household they inhabit apart from their children, reducing their complexity through use as though they were household tools. As slaves of their parents, the children cannot express the tragedy which lies secluded in the entropy of their unconscious.

As a thermodynamic property defined statistically, entropy describes the number of possible microcosmic states of a system, as well as the process through which the number of possible states is reduced through the passage of time. As entropy increases, the number of possible states and the complexity of the system decrease. Information measures the complexity of these microcosmic states while entropy measures our uncertainty of them. Though if the difference between entropy and information is relative to the observer, could information simply depend upon our arbitrary knowledge of complexity, with entropy depending upon our arbitrary ignorance of complexity? Claude E. Shannon, pioneer of information theory, inverted the classical opposition between entropy and information with a mathematical theory of their identity, which built upon the discoveries of statistical mechanics in the field of telecommunications. According to Shannon's theory, the more distorted a signal becomes through its transmission, the more noise it carries along its channel, and the more uncertain is the message. Yet the more uncertainty there is in a signal, the more freedom of choice there is in selecting the message from out of its noise, resulting in more and not less information present (Shannon \& Weaver, 1964: 18-19). Therefore an increase of information will always accompany an increase of external noise. This use of entropy depends upon the receiver's 
knowledge and ability to guess the possible meaning of the message, in order for the message to be reconstituted out of the noise-information.

While information theory was instrumental in bringing about the digital revolution in electronics, it has also been appropriated for more metaphorical uses in the humanities. Lyotard, for instance, identifies the stunted development of the Third World with the entropic source of reduced complexity and Western domination with the receiver's ability to make use of this reduced complexity. Against Luhmann, who defines communication as the unity of information, message, and understanding while excluding the uncertainty of noise, Lyotard ostensibly identifies noise with the oikeion, to the extent that the source of the message which it equivocally communicates is lacking in selfreferentiality. Shannon, an electrical engineer not particularly interested in the possible applications of his theory outside of their intended use in informatics, has nonetheless influenced how theorists in the humanities understand communication in a very general sense, especially regarding the distinction between information and message, and the importance of noise in communicating messages. While Lyotard himself does not mention Shannon's concept of noise in relation to the oikeion, its inherent ambiguity, neither desirable nor undesirable outside of the system's view to reducing complexity, might be linked metaphorically to the oikeion and its secluded, not yet autonomous generation of complexity. Luhmann, on the other hand, is only concerned with noise to the extent that it provides more complexity to reduce and more information from which to select meaning. But there is a difference between the self-legitimating selections of meaning from within a system and the order which noise can spontaneously generate on its own, just as there is, for instance, between media reports on world events and the real 
events themselves. While Luhmann might exclude noise on the basis of a self-referential code which determines the functioning of the system, Lyotard aims to listen to those very dysfunctional messages which are systematically excluded, in order to recuperate the oikeion which refers to the other before it can refer back to any self.

In his appropriation of the term "ecology", Lyotard plays off the ambiguity between environment and the asymmetrical relation of familiarity in order to reformulate it as a discourse of the secluded, with the aim of listening to the oikos, rather than describing it (Lyotard, 1993: 101). The secluded whom he names are women, children, and animals. As oikeion, however, they could never be named, which is why they must be listened to instead. The monadological aspect of the oikeion corresponds to their seclusion from the system, since a monad has no windows upon the world and instead only contains a limited perspective of the world within itself, always risking falling into another monad's sphere of appurtenance for its own lack of self-knowledge or selfreferentiality. It becomes secluded for being unable to make use of its memory and naked for having no appurtenances of its own, since a monad can only extend beyond itself into the field of action and express its will to the extent that it is able to select from a complex memory. The perspective of the monad is determined by this "reduction of complexity", while entropy determines the equivocal information which falls outside of its perspective, or the potential oikeion of an observer who watches closely and listens carefully. It is in this sense, perhaps, that we might grant monads the possibility of having windows after all. 


\section{Bibliography}

Deleuze, Gilles. 1993. The Fold: Leibniz and the Baroque, translated by Tom Conley. Minneapolis: University of Minnesota Press.

Leibniz, Gottfried Wilhelm. 1976. Philosophical Papers and Letters, edited and translated by Leroy E. Loemker. Dordrecht: D. Reidel Publishing Company.

Luhmann, Niklas. 1989. Ecological Communication, translated by John Bednarz, Jr. Chicago: University of Chicago Press.

_. 1995. Social Systems, translated by John Bednarz, Jr. with Dirk Baecker. Stanford: Stanford University Press.

Lyotard, Jean-François. 1984. The Postmodern Condition : A Report on Knowledge, translated by Brian Massumi. Minneapolis. University of Minnesota Press.

Lyotard, Jean-François. 1988. The Inhuman: Reflections on Time, translated by Geoffrey Bennington and Rachel Bowlby. Minneapolis: University of Minnesota Press.

Lyotard, Jean-François. 1993. Political Writings, translated by Bill Readings and Kevin Paul Gaiman. Minneapolis: University of Minnesota Press.

Shannon, Claude E. Weaver, Warren. 1964. The Mathematical Theory of Communication. Urbana. University of Illinois Press. 